\title{
El cristianismo como educación del género humano en Fichte
}

\author{
Christianity as an education of humanity in Fichte
}

\author{
Salvi Turró \\ salvi.turro@ub.edu \\ (Universitat de Barcelona, Barcelona, Espanha)
}

\begin{abstract}
Resumen: A partir del precedente de Lessing, se analiza la comprensión del cristianismo en Fichte como proceso educativo de la humanidad, subrayando la proximidad y diferencias entre ambos autores. Religión del mundo antiguo, mensaje de Cristo y cristianismo racional son las fases de tal desarrollo. Finalmente, se destaca la herencia cristiana en la comprensión en del método genético de la Doctrina de la Ciencia, así como el horizonte hermenéutico que también caracteriza la posición de Fichte.
\end{abstract}

Palabras clave: Fichte; Lessing; filosofía de la religión; filosofía de la historia; cristianismo.

\begin{abstract}
Starting from Lessing's precedent, the understanding of Christianity in Fichte as an educational process of humanity is analysed, underlining the proximity and differences between the two authors. Ancient world religion, message of Christ and rational Christianity are the phases of such development. Finally, the Christian heritage is highlighted in the understanding of the genetic method of the Doctrine of Science, as well as the hermeneutical horizon that also characterizes Fichte's position.
\end{abstract}

Keywords: Fichte; Lessing; Philosophy of Religion; Philosophy of History; Christianity.

DOI: http://dx.doi.org/10.11606/issn.2318-9800.v25i2p173-191

El título de esta contribución remite al conocido ensayo de Lessing de 1777/1780. Que Lessing pueda ofrecernos un hilo conductor para exponer a Fichte no es casual. ${ }^{1}$ El filósofo, durante sus últimos años en Pforta y primeros en la universidad, no sólo se familiarizó con las polémicas teológicas de los Antigöze hasta el punto de hacer de Lessing "objeto de veneración" y proyectar incluso un viaje para conocerlo personalmente, sino que, según testimonio filial, el "modo de pensar" del Fichte de madurez contiene indudables "trazas de afinidad espiritual" con Lessing (Fuchs, 1978, p. 17). Y, en efecto, no ya el tema de la educación en general, sino específicamente el papel de la religión en la formación del género humano recorre todo Fichte: desde

1 Este articulo puede considerarse una explicación detallada de lo que apunté en otro lugar: que el "milenarismo religioso-filosófico de Fichte no deja de ser un fruto maduro de la simiente sembrada por Lessing y su 'nuevo evangelio eterno' de la 'tercera edad del mundo'” (Turró, 2019b, p. 291). Si allí me ocupaba del papel político del cristianismo en el desarrollo histórico del Estado y su necesaria superación final, aquí abordaré la vertiente estrictamente educativa del tema a partir de su indudable matriz lessingniana. 
la apelación de 1793 al "gran educador de la humanidad" que ha dispuesto "todos los acontecimientos del mundo como cuadros aleccionadores para que la humanidad aprenda cuanto le es preciso saber" (BfR, 203), ${ }^{2}$ hasta la vinculación entre moralidad y papel educador de la iglesia en 1812 con una referencia explícita a que "el género humano ha sido educado por Dios” (SL, 337), o hasta la definición del cristianismo en 1813 como auténtica “institución educativa” (VaPh, 171). Expresiones todas ellas que se sitúan claramente en el horizonte conceptual abierto por el ensayo de Lessing.

No me interesa discutir aquí si Die Erziehung des Menschengeschlechts constituye una obra "impenetrable" y "en modo alguno unívoca" en relación al pensamiento de su autor (Barr, 2013, p. 85), o si por el contrario es perfectamente conciliable con las tesis de sus otros textos como, p.e., con la parábola del anillo en Nathan der Weise (Vollhardt, 2018, p. 345). Al margen de cuál sea el significado de ese ensayo en relación al conjunto de su pensamiento, lo cierto es que en aquel ensayo "se lleva a cabo una síntesis de lo histórico y lo racional; lo histórico no constituye ya lo contrario de lo racional, sino que es el camino de su realización y de su lugar propio, único posible de su cumplimiento” (Cassirer, 1943, p. 219). Perspectiva que no podía pasar desapercibida a Fichte, en especial el de la segunda época, con su comprensión de la historia como Erscheinung de lo Absoluto. Y, en efecto, una tesis es manifiesta en el texto de Lessing: que la "revelación es la educación que ha acontecido y aún acontece al género humano" (EM, §2) $)^{3} 0$, de modo menos ambiguo - como se lee en la nota preliminar del autor camuflado en editor de la segunda edición ${ }^{4}$-, que “en todas las religiones positivas” puede vislumbrarse "el curso según el cual, única y exclusivamente, podía desarrollarse el entendimiento humano en cada lugar" (EM, Vorbericht). Esta historicidad de la razón se concreta en tres períodos: el Antiguo Testamento con su religión de premios y castigos externos, el Nuevo Testamento como religión vinculada a la interioridad de la conciencia y la culminación del proceso en la tercera edad del mundo o nuevo evangelio eterno.

A mi parecer, estas tres fases de la historia religiosa como educación del género humano coinciden con el modo de proceder de Fichte en los textos sobre esa temática en su segunda época: ${ }^{5}$ básicamente, Die Grundzüge des gegenwärtigen

\footnotetext{
2 Citamos las obras de Fichte según se indica en la bibliografía. Las traducciones son todas mías.

3 Citamos el ensayo de Lessing según se indica en la bibliografía. Las traducciones son todas mías.

4 Andreu (1982, p. 595-597) ha explicitado el sentido que pueda tener para Lessing editar su propio texto como si fuera de otro autor.

5 Sólo nos referiremos tangencialmente a la Anweisung zum seeligen Leben de 1806 porque su tratamiento de la religión y del cristianismo no se hace desde la perspectiva histórico-educativa de la humanidad, sino que se ocupa de la experiencia cristiana de lo divino en relación a los principios rectores de la Doctrina de la Ciencia según las exposiciones de 1804 y 1805 y, por tanto, en continuidad con la disciplina fundamentadora última: "la Anweisung es, de los tres escritos populares [publicados en 1806], el único que delata explícitamente el desarrollo de la Doctrina de la Ciencia [...]; es, por tanto, la mejor introducción pensable a la misma Doctrina de la Ciencia; además es doctrina de la religión" (Asmuth, 1999, p. 19).
} 
Zeitalters de 1805, la parte final de la Sittenlehre de 1812 y la última sección de las Vorlesungen aus der angewendeten Philosophie de 1813. Ciertamente tanto la fundamentación como muchas de las tesis concretas de Fichte van más allá de Lessing y se insertan conceptualmente en el corazón de la Doctrina de la Ciencia, pero, como mostraremos, el esquema general del despliegue histórico de la religión y su sentido formativo es común a ambos: cosa no baladí en un autor para el que pensar es esencialmente esquematizar. Centrándonos en las tres obras antes mencionadas, haremos uso del esquema lessingniano como hilo conductor para la reconstrucción de la doctrina de Fichte sobre la religión en tanto que acontecer histórico-pedagógico y, en especial, acerca del papel educativo del cristianismo. Dividiremos la exposición en tres apartados: el cristianismo como educción moral, el cristianismo como enseñanza especulativa, implicaciones de la convergencia entre cristianismo y Doctrina de la Ciencia.

A un pueblo, como el israelita primitivo, "rudo, inhábil para pensamientos abstractos y sumido en la infancia" sólo podía corresponder una educación moral “mediante castigos y recompensas sensibles" (EM, \$16). Por ello su religión consistía en una "heroica obediencia ciega que observa las leyes de Dios meramente porque son leyes de Dios” (EM, §32). Diktat sin restricciones ni condiciones, que implica una divinidad que "da testimonio de sí a través de milagros, siendo más poderosa que cualquier otro dios" (EM, \$12). Y todo ello sin el menor atisbo de conciencia o responsabilidad individuales, pues aquella religión versaba sobre "promesas y amenazas divinas que se referían al Estado en su conjunto" (EM, \$29). Tal es la caracterización que ofrece Lessing del Antiguo Testamento como mera religiosidad externa-estatutaria propia de la infancia humana.

La similitud con la caracterización fichteana del mundo antiguo en las VaPh casi no precisa de mayores comentarios: "el Estado y su constitución son un mandato divino absoluto sobre el cual no hay que cavilar más, y que recusa completamente al entendimiento; una cuestión de fe para todos: fe natural en el fundador, fe en la autoridad en sus subordinados" (VaPh, 113). La divinidad, como dios tutelar del linaje o ciudad (VaPh, 116) que se manifiesta en portentos y prodigios (VaPh, 113), es inherente a una organización social basada en un culto a la vez político y religioso (VaPh, 111-112) y que sólo reclama obediencia ciega (VaPh, 110). Totalidad teológicopolítica en que "los individuos sólo existían en el orden estatal, como miembros de la unión y como medios para ese fin; por la voluntad de Dios el individuo era absorbido por el Estado" (VaPh, 113).

Volvamos a Lessing. Una vez disciplinado externamente, el hombre se encontró en situación de "necesitar y poder disponer de motivaciones más nobles que las 
recompensas y castigos temporales con que había sido dirigido hasta entonces" (EM, §55). Ello exigía la aparición de un “pedagogo mejor” (EM, §53), Cristo, “el primer y auténtico maestro práctico" (EM, §58) que puso el criterio de moralidad en "una pureza interior del corazón en vistas a otra vida” (EM, \$61). Con Cristo y el mensaje de los escritos neotestamentarios, segundo "libro elemental para el género humano" (EM, §64), se deja atrás la era de la mera coacción político-religiosa para entrar en la segunda edad del mundo, la de la verdadera moralidad.

Subrayando aún más que Lessing la diferencia radical, si no ruptura, entre estos dos períodos, también para Fichte el nuevo mundo se inaugura con la predicación y enseñanza de Cristo. ${ }^{6}$ Con él se altera de raíz la comprensión de la divinidad, del hombre y del mismo Estado. En lugar del Dios-autoridad que dicta arbitrariamente las normas conductuales y cultuales, se pone un "ser santo determinado por su esencia interna" que no precisa de "ningún intermediario" (VaPh, 132) y, por tanto, un Dios que nos libera de la fe y obediencia ciegas y de los rituales externos como instrumento de santificación. El evangelio es una enseñanza de libertad, igualdad, reconciliación y perdón dirigida a todo el género humano (VaPh, 132). Es la humanidad, y no la pertenencia al linaje o la ciudad (VaPh, 117-118), lo que ahora constituye el fundamento de las instituciones religiosas y políticas. Por ello, el reino de los cielos es la "visión fundamental del cristianismo" (VaPh, 131), su "unidad conceptual esencial" (VaPh, 136), que determina el sentido último de la predicación de Cristo y de la evolución histórica de la humanidad formada en su seno: conseguir progresivamente que "todos los seres humanos sean simplemente verdaderos cristianos y ciudadanos del reino de los cielos, y que todo otro dominio sobre los hombres desaparezca pura y completamente" (VaPh, 163).

Fichte expone detalladamente los efectos determinantes que ha tenido el cristianismo en el proceso formativo de la humanidad. De entrada en la humanidad europea: ${ }^{7}$ los pueblos germánicos que irrumpieron en el Imperio Romano se educaron en el seno de la iglesia cristiana y, por ello, más allá de su fragmentación en naciones rivales, se fraguó una verdadera comunidad fundada en los valores de la libertad y la igualdad de todo ser humano. En expresión de Fichte, se conformó un auténtico

\footnotetext{
6 La reconstrucción del mensaje de Cristo por parte de Fichte es deudora de los inicios de la crítica neotestamentaria debidos a Reimarus y popularizados por Lessing en sus Fragmentos de un desconocido (1774-1777). No obstante y como se verá a continuación, su comprensión del texto evangélico y de su enseñanza coincide sorprendentemente con resultados de las investigaciones histórico-críticas recientes: los Evangelios no suministran ninguna biografía de Jesús y, por tanto, no pueden ser leídos como informaciones históricas literales; Jesús manifestó poseer una intimidad especial con Dios que dotaba a su menaje de la autoridad de una experiencia vivida; la categoría central de la predicación de Jesús fue la del reino de los Cielos/de Dios entendido según la estructura proyectiva del ya está entre vosotros, pero todavía no se ha realizado íntegramente. Véase al respecto: Bultmann (1958) y Jeremias (1971).

7 Para una exposición más detallada de la comprensión fichteana de la historia europea y del desarrollo del Estado racional, véase Turro (2013 y 2019a).
} 
“imperio cristiano" (GgZ, 349) o una "república cristiana” (GgZ, 350) de pueblos, pudiéndose afirmar que "los pueblos cristianos europeos constituyen en esencia un solo pueblo, reconocen en Europa su única patria verdadera" (GgZ, 358). En esta comunidad "la religión se convirtió en la supervisora del derecho de gentes" estableciendo sus principios básicos: aceptación de la soberanía de cada territorio, prohibición de guerras de exterminio y necesidad de instaurar progresivamente una paz permanente (GgZ, 349). Por ello, aún después de disolverse el imperio medieval en las nuevas monarquías nacionales, aquella herencia pervivió en la medida que "cada Estado tiende a la monarquía universal cristiana o, cuanto menos, a tener la capacidad de tender a ella" (GgZ, 357).

Por otro lado, el evangelio de reconciliación nos orienta a lograr una organización interna del Estado según los principios políticos del republicanismo: "el reino del derecho exigido por la razón y el reino de los cielos en la tierra prometido por el cristianismo son uno y el mismo" (VaPh, 164). Pero también exige, por la dimensión irreductiblemente universal de ese reino, que el derecho se extienda a todos los Estados del mundo y que, a su vez, esos Estados establezcan relaciones jurídicas y no violentas entre ellos. De este modo, la formación de los pueblos europeos en el crisol del cristianismo deviene dinamismo teleológico de la humanidad entera: "así, todo el género humano sobre la tierra será abarcado por un único Estado cristiano internamente federado" (VaPh, 177).

Ahora bien, el mensaje de Cristo no se limita a predicar un comportamiento según leyes universales, sino que exige la pureza de corazón, afecta a la intención de la voluntad: hay que actuar por la "intelección clara del entendimiento individual de cada cristiano" (VaPh, 132). Ahí radica precisamente la inversión radical del mundo antiguo y de su legalismo externo. El cristianismo forma la conciencia para la verdadera y única moralidad interior auténticamente libre. En este punto fue decisiva, según Fichte, la labor de Lutero: con la Reforma, "el pueblo alemán” ha llevado a cabo su "última gran acción completa y universal” (RdN, 171). Frente a la decadencia espiritual y el poder temporal del papado se restauró el principio cristiano en su integridad original, que "nada tiene que ver con cambiar sólo el mediador externo entre el hombre y Dios, sino que simplemente no se requiere mediador alguno, pues tal vínculo se ha de hallar en uno mismo" (RdN, 175). Con esta reactualización de la pura moralidad interior, se hace del todo evidente que la noción del reino de Dios sobrepasa el ámbito del derecho y del Estado como institución necesariamente coactiva (VaPh, 171) y que, por tanto, la formación de la humanidad no puede detenerse en lo meramente jurídico, sino que ha de avanzar hasta que, ad limitem, "en algún momento y lugar en el reino del cristianismo languidecerá de forma gradual el gobierno tradicional de la coacción [...]; y así, el actual Estado coactivo, al no manifestarse ninguna fuerza en su contra y por su propia futilidad, 
fallecerá sosegadamente a lo largo del tiempo" (VaPh, 176). Ante este č $\sigma \alpha$ đov moral del género humano fomentado por el cristianismo, no es de extrañar que el editor de las $\mathrm{VaPh}^{8}$ anotara los pasajes finales del texto fichteano con citas de Apocalipsis (VaPh, 204): “Y los pueblos, que allí [en la Jerusalén celestial] serán bienaventurados, marcharán en su luz; y los reyes de la tierra le llevarán en su gloria” (Ap 21, 24).

III

Ahora bien, en el esquema histórico-educativo formulado por Lessing, la predicación de Cristo como maestro [Lehrer] no sólo tiene una dimensión práctica en tanto que educación moral de la humanidad, sino que es también enseñanza [Lehre] porque transmite una doctrina [Lehre]: doctrina sobre la inmortalidad del alma (EM, §58-62), sobre la unidad y trinidad de Dios (EM, §71-73) y sobre la satisfacción del pecado por el Hijo de Dios (EM, §74-75). Ciertamente estas tesis religioso-metafísicas no fueron formuladas por Cristo y sus discípulos a modo de pura “especulación filosófica” (EM, \$60). Como en toda religión positiva tales enseñanzas se transmitieron, no como "verdades abstractas", sino con el "revestimiento de alegorías y de aleccionadores casos concretos contados como efectivamente acaecidos" (EM, §48). No obstante, por tratarse de doctrinas necesariamente verdaderas por vincularse a la más perfecta moral, en su misma formulación inicial como revelación (religión positiva) se hallaba contenido el sentido de su evolución futura: alcanzar un "estadio superior de ilustración y pureza” (EM, §48). De pureza porque se realizará plenamente la moralidad interior, de ilustración porque se conseguirá "la transformación de las verdades reveladas en verdades racionales" (EM, §76). Según Lessing estamos justamente entrando en esta "tercera edad del mundo" (EM, § 88), que ya profetizaron algunos exaltados del siglo XIV como tránsito a un nuevo evangelio eterno (EM, §86-87): “tiempo de plenitud” (EM, §85) en que la educación religiosa recoge sus frutos en el advenimiento íntegro de la racionalidad teórica y práctica del género humano.

También en Fichte la enseñanza de Cristo no es sólo práctico-moral sino teórico-doctrinal: "el cristianismo es así y ante todo una enseñanza; se impone la tarea de formar el entendimiento de los hombres [...] para una intelección cierta y absoluta de la relación de la humanidad con Dios" (VaPh, 133). Por eso el cristianismo, en relación a las cinco visiones del mundo detalladas en la AsL, va más allá de la moralidad superior para situarse propiamente en la visión religiosa, definida por su íntimo parentesco con la ciencia filosófica: "el punto de vista científico y religioso son simplemente reflexivos y contemplativos, en modo alguno prácticos y activos; son una visión firme y serena que permanece en el interior de la mente" (AsL, 112). Veamos

8 En Turró (2017, p. 48-54) se analiza detalladamente la génesis e historia editorial de este curso, así como su significado teológico-político. 
cómo tematiza Fichte el modo como se formuló la enseñanza doctrinal cristiana, los mecanismos educativos de su transmisión y su elevación final a verdad filosófica por la Doctrina de la Ciencia: en suma, cómo el cristianismo ha sido también educador racional, y no sólo moral, del género humano.

La sección final de la SL está consagrada en gran parte a comprender el sentido de la transmisión del cristianismo desde su fundación. En Cristo "acaeció, de manera inconcebible y sin vinculación con ningún elemento precedente, la irrupción originaria de algo que aún no existía en lugar alguno del mundo” (SL, 382). El mensaje absolutamente novedoso de Cristo sólo puede entenderse por su genialidad, por su inspiración, por su carácter revelado (SL, 382, 390). Y, en efecto, desde las lecciones públicas de 1794-95, Fichte ha definido la producción genial del espíritu como "la capacidad [...] de elevar a conciencia sentimientos relativos a un orden suprasensible de cosas" (VGB, 323) que permite una experiencia inmediata de la belleza originaria, lo sublime primordial, la verdad eterna o la divinidad (VGB, 319). Por ello se decía ya entonces que para el "desarrollo de la humanidad" es preciso que su "guía y educador tenga espíritu" (VGB, 322). Se comprende que ahora se afirme que Cristo, verdadero "genio artístico o práctico" (VaPh, 139), tenía de su doctrina una certeza que emanaba directamente de sí mismo y de su intimidad con Dios: "él obtiene su convicción mediante la experiencia inmediata de sí mismo" (VaPh, 146) y apela a una "prueba interior" (VaPh, 145) que procede de una "mirada intelectiva clara [klare Einsicht]" (VaPh, 132).

Ahora bien, la transmisión histórica, en tanto que "reciprocidad continuada" que atraviesa la "memoria viva eterna del género humano que conecta lo nuevo con lo viejo" (SL, 381), sólo se produce si el espíritu se hace letra, siendo la letra el lenguaje compartido por la comunidad. Todo proceso educativo y de transmisión cultural está mediatizado así por la tradición y la escritura (SL, 381). El mensaje de Cristo tuvo, pues, que hacerse escritura: “los escritos inmortales del Nuevo Testamento” (VaPh, 137). Necesariamente la escritura ha de ser leída e interpretada: se requiere, pues, un acuerdo en lo esencial de la doctrina común, un símbolo que exprese las verdades fundamentales del mensaje cristiano (SL, 381) ${ }^{9}$. Con ello, empero, lo que en Cristo era clara evidencia interior se convierte en objeto de creencia para sus sucesores: creencia en la verdad histórica de los textos neotestamentarios y credo o símbolo de la fe que delimita la comunidad eclesial. Fijación del canon de escritos sagrados, formulación del símbolo de fe en los primeros concilios y la Reforma como retorno a la escritura son sendos momentos históricos de este proceso institucionalizador (GgZ, 272-273).

\footnotetext{
9 En estos pasajes Fichte reúne fructíferamente dos sentidos de término símbolo: por su connotación estética, todo proceso de esquematización simbólica remite a lo suprasensible y puede atribuirse así a Cristo como genio fundador; por su connotación teológica remite al uso del término por los padres griegos de la Iglesia, designando entonces la fórmula de fe (Credo) en que se expresa la identidad y pertenencia a la comunidad.
} 
Pues bien, desde que el evangelio y el símbolo se constituyen en instrumento formador de la comunidad y transmisor de la doctrina de Cristo, sucede lo que toda letra necesariamente conlleva: apropiación exterior del mensaje y desvirtuación de su sentido originario. El "abismo entre la doctrina auténtica de la revelación y el símbolo de la iglesia" (SL, 383) es la fuente de la imperfección, confusiones e incluso errores que acompañan el desarrollo histórico del cristianismo (SL, 383-384). Si la doctrina de la creación es ciertamente uno de los errores fundamentales denunciados por Fichte (AsL, 118), en los GgZ indica la causa última de tales deformaciones: la interpretación paulina de la figura de Jesús. Partiendo del Dios terrible y vengativo del Antiguo Testamento que, como en el mundo antiguo en general, se reserva un pueblo mediante un pacto y un sistema legal-coercitivo de conductas y culto, Pablo hace de la muerte de Jesús la clave del cristianismo: ella significa el fin del pacto con los judíos y el establecimiento de uno nuevo con los gentiles (GgZ, 270). En una posición diametralmente opuesta a lo que será la hermenéutica hegeliana, para Fichte esta theologia crucis, lejos de ser asumida especulativamente por la razón viernes santo como imagen de la positividad de la negación dialéctica -, corrompe el sentido liberador del evangelio de la igualdad y la reconciliación. ${ }^{10} \mathrm{Y}$, en efecto, amparándose en aquella teología, Pablo restauró, por un lado, la imagen del Dios antiguo que sólo se satisface con "sacrificios de lo que es más apreciado por los hombres, mortificaciones, incluso la sangre del hijo unigénito si es necesario" (GgZ, 227); y por otro, instituyó un nuevo legalismo, la autoridad eclesial y la creencia como base de la religión.

Ahora bien, la revelación original de Cristo llevaba en su seno la apelación a la libertad y la mirada intelectiva [Einsicht] como base del convencimiento interior de cada cristiano y, por tanto, a pesar de las deformaciones, "en el símbolo radica una verdad, tan cierto como que es símbolo" (SL, 383). Por tanto, el auténtico cristianismo no podía consistir sólo en la repetición mecánica del símbolo como objeto de una fe coactiva externa, sino que exigía la reactualización de la evidencia originaria que tuvo Cristo de su doctrina: "el símbolo es perfectible" (SL, 381). Consiguientemente, el objetivo formativo último de la iglesia sólo podía consistir en alcanzar la intelección de la verdad oculta en su símbolo: sus maestros "no han de quedar cautivos del símbolo", lo han de elevar a lo que hay "sobre todo símbolo y toda iglesia”, a la ciencia filosófica (SL, 381). Con ello, lo que para Cristo era verdad presente inmediatamente a su espíritu genial se convertirá para nosotros en "algo metafísico" (VaPh, 140), i.e. algo fundado racionalmente. En clara afinidad al esquema de Lessing, también para Fichte ese momento de racionalización de la fe

10 Tilliette subraya certeramente esta eliminación completa del valor redentor de la cruz en Fichte: "el cordero lleva el pecado del mundo, pero no es inmolado; su sangre se mezcla con la sangre de nuestras venas, es su vida en nosotros y no su sangre derramada; metamorfosearnos en Cristo es, como él, transformarnos en Dios, revestirnos de la luz y de la vida divina” (2003, p. 252). 
ha llegado: gracias a la existencia "de un público científico en el seno de la iglesia" (SL, 385) - la ilustración transformada en Doctrina de la Ciencia - finalmente "el entendimiento gana terreno a la fe hasta que la haya aniquilado completamente y haya acogido su contenido en la forma más noble de la intelección clara" (VaPh, 108).

A diferencia de Lessing, Fichte no sólo enuncia esta tarea sino que emprende su realización. La labor implica metodológicamente dos operaciones: por un lado, la crítica de los textos bíblicos y de su interpretación para aproximarse al sentido original (SL, 388-389); por otro lado, la transformación del sentimiento religioso y de la fe moral en auténtica mirada intelectiva capaz de dar razón de lo creído (SL, 389-391). En la AsL el evangelio de Juan - "maestro del auténtico cristianismo" y "el único con el que el filósofo puede coincidir, pues sólo él respeta la razón y apela a la única prueba que vale para el filósofo, la interior" (AsL, 116) - permite elaborar una doctrina filosófica de la religión en torno a la relectura del Lógos y el amor joánicos. A su vez, en las VaPh los dogmas centrales del cristianismo se interpretan a la luz de la metafísica de la manifestación. ${ }^{11}$ Fichte los reduce a tres: como en el caso de Lessing, la Trinidad y la doctrina de la justificación; a diferencia de Lessing, la inmortalidad del alma cede su puesto a las profecías milenaristas que afectan a la humanidad entera - modificación que, sin duda, obedece a la dimensión necesariamente intersubjetiva del reino de Dios y su consumación escatológica, como intersubjetivos son también, en el plano racional, la moralidad y el derecho.

El dogma trinitario, eje del símbolo de fe, expresa que lo Absoluto, "lejos de ser el Dios abstracto del concepto puro, que no se manifiesta", es en verdad "el Dios vivo inmediatamente en el interior del hombre - el Dios que así se manifiesta" (VaPh, 148): expresa, por tanto, que la divinidad ex-siste en la conciencia como su imagen. Si la figura del Padre simboliza el ser eterno e inconcebible de Dios, el Hijo y el Espíritu se refieren al ámbito de la manifestación. La manifestación fáctica e histórica del Dios vivo es lo que acaeció con la figura del Hijo-Cristo. Él es el primer hombre que tuvo una intelección clara de la presencia liberadora de Dios en el interior de la conciencia, y su mensaje determinó la historia posterior de la humanidad. Pero su mirada intelectiva era experiencia vivida, en absoluto doctrina demostrada. Pues bien, el Espíritu es la "disposición natural para lo suprasensible que radica en el conjunto del género humano" (VaPh, 157). Esta disposición universal -también manifestación de Dios -, al ser despertada por Cristo de su somnolencia legal-ritual en el mundo antiguo, pudo elevarse progresivamente - por la mediación de la forma intelectiva socrática y el impulso decisivo de Kant (VaPh, 158) - a conciencia explícita y filosóficamente demostrativa de la verdad del mensaje del fundador: merced al Espíritu, la visión fáctica de Jesús se convierte en metafísica. En suma,

11 El estudio histórico y sistemático más completo sobre la dogmàtica cristiana y su reelaboración por parte de Fichte es el de E. Brito (2004). 
el Padre es lo natural, lo absoluto en su manifestación, lo universalmente pre-dado; el Hijo es la elevación fáctica de ello a imagen del mundo suprasensible; el Espíritu es el reconocimiento y descubrimiento de este mundo por la luz natural del entendimiento (VaPh, 157).

La doctrina de la justificación también muestra su verdad si se interpreta a la luz de la cesura entre el mundo antiguo y la novedad del evangelio. El descubrimiento de la libertad y el perdón puso de manifiesto que el hombre no necesita de "la circuncisión, inclusión en los misterios, la consagración a Isis, Osiris, etc." (VaPh, 151) para salvarse, sino que Dios nos acoge a todos por igual. La enseñanza de Cristo nos redimió ciertamente de la religiosidad basada en la "distinción entre excluidos y elegidos, pecadores y justos [...], la circunstancia de nacimiento y de linaje” y, por tanto, de la imagen de un Dios “déspota arbitrario, obstinado, que ordena sin razones y al que hay que obedecer sin intelección" (VaPh, 151). Pero es erróneo pensar la justificación como redención del pecado personal a la manera del luteranismo. Cristo redime de la religión del culto externo, pero con ello abre el ámbito de la verdadera santificación como ejercicio exclusivo de la libertad personal. Afirmar que Cristo salva del mal obrar porque cada uno es justificado por la fe es lo que "dicen insensatamente los modernos creyendo que así hablan de manera piadosa y edificante" (VaPh, 151).

Respecto a la escatología apocalíptica, hay que reconocer que sus imágenes, aun afectando al sentimiento y moviendo así a la actuación en pro del reino de Dios, en la literalidad con que eran afirmadas por la tradición - fin del mundo en fuego, reaparición personal de Jesús, resurrección de los muertos o Juicio final (VaPh, 162) -, han quedado superadas y son hoy claramente ininteligibles (VaPh, 162). Ahora

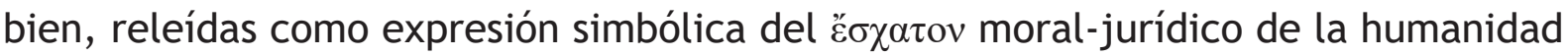
en su unión final en una sociedad cosmopolita, “concuerdan con lo que al comienzo de esas lecciones, a partir de la filosofía, hemos reconocido como la tarea de la libertad" (VaPh, 163). De modo semejante a Lessing, las doctrinas milenaristas, adecuadamente reinterpretadas, pueden "ser retomadas como la verdadera clave de bóveda y punto culminante del cristianismo" cuya verdad y necesidad muestra la Doctrina de la Ciencia (VaPh, 163).

Con el tránsito del símbolo a su explicitación racional se da cumplimiento a la llamada evangélica a la libertad y a la convicción interna de la mirada intelectiva como única fuente de certeza. Pero, con ello, se abre una nueva etapa en el proceso educativo del género humano: ahora es el filósofo quien hereda y asume la tarea formativa como progresiva racionalización del mensaje cristiano que, en su literalidad fáctico-histórica, queda de algún modo atrás. El mismo Jesús, aun siendo un momento único y necesario en el proceso de manifestación de Dios, ha de ceder su puesto al Espíritu o entendimiento universal del que emana la Doctrina de la Ciencia: llegados aquí en la educación del género humano, la fe eclesial-positiva 
"aparta del verdadero cristianismo exactamente igual que la insistencia en la fe en la persona de Jesús" (VaPh, 149). ${ }^{12}$ Como en Lessing, pues, el libro elemental del Nuevo Testamento culmina en el evangelio eterno de la razón. Lo cual significa que a partir de ahora habrá de distinguirse entre una iglesia centrada en la "absoluta inmodificabilidad del símbolo" y en la "fe en la autoridad del testimonio" (SL, 385) y la "verdadera iglesia" que, reelaborando filosóficamente la verdad fáctica del cristianismo, configura un nuevo "eslabón en la cadena de formación progresiva del género humano" (SL, 388). En suma, se inaugura el tiempo de plenitud de la "cuarta confesión" o "religión cristiana universal”, que constituía una de las tesis proyectivas de Die Republik des Deutschen. ${ }^{13}$ Este nuevo cristianismo está llamado a convertirse en la "religión civil" del Estado de derecho y, dada la incardinación de éste en las estructuras internacionales, será el fermento futuro de la necesaria superación moral del Estado en una única sociedad cosmopolita y en una sola iglesia como "comunidad puramente moral y creyente" (PhM, 440). El filósofo, ciertamente, "permanece miembro de la iglesia por haber sido engendrado en su seno" (SL, 390), pero ello sólo expresa su situación fáctica de partida. Atendiendo a su misión de elevar a ciencia la manifestación histórica de la verdad, el filósofo está destinado a una tarea más elevada: convertirse en el maestro del nuevo cristianismo racional. El mismo estamento académico que legitima la soberanía con su tarea formativa (VaPh, 77) es llamado, pues, a ser el cuerpo educativo de la conciencia religiosa de la humanidad. Fichte cierra así el círculo de su vocación vital: de la llamada juvenil a convertirse en "predicador" del kantismo $(\mathrm{B}, 172)$ a la comprensión madura de sí mismo como "sacerdote de la ciencia" (WG, 131). ${ }^{14}$

\section{IV}

¿Cómo interpretar el sentido último de esa transformación del cristianismo en educación religioso-racional del género humano mediante los principios de la Doctrina de la Ciencia? De hecho este interrogante afecta no sólo a la comprensión

12 En este sentido, según Tilliette (2003, p. 259), en Fichte debería hablarse más de Jesusología que de Cristología. Rametta (2003, p. 154) se ha ocupado de la relación entre esta reducción de Cristo a lo fáctico-histórico y la tesis paralela de la superación del Estado como fin de la historia.

13 "Los legisladores, por un lado, encuentran las tres confesiones reconocidas. Por otro lado, consideran como necesario que se ha de promulgar y reconocer claramente una cuarta confesión, y elevarla a auténtica religión civil, a religión legítima para la tarea del Estado. Esta nueva confesión se denomina religión cristiana universal, expresada con el nombre alemán y dejando al margen el [nombre griego] de católica. Se caracteriza por reconocer como verdadera la doctrina de Dios del cristianismo porque y en la medida que concuerda con la propia razón. Contrariamente, los que permanecen en la confesión antigua no lo sostienen por sí mismos, sino porque le dan crédito. [El cristianismo universal] rememora la persona de Jesús con honor, sin entrar en modo alguno en la polémica histórica que [considera] una banalidad; respeta a cualquiera [de las otras confesiones] y las reconoce" (RD, 397).

14 X. Léon (1922) ha expresado certeramente esta dimensión profético-sacerdotal de la obra fichteana en el subtítulo de su primer volumen: "Establecimiento y predicación de la Doctrina de la Libertad". 
de la historia de la formación de la humanidad, sino al estatuto de la misma filosofía primera como metafísica de la manifestación del Absoluto en su imagen y, por tanto, al núcleo especulativo del proyecto fichteano al menos en su segunda época. Al respecto las posiciones de los comentaristas son divergentes. Por la derecha tenemos la interpretación que ve en la Doctrina de la Ciencia una filosofía cristiana, aunque no se trate literalmente del cristianismo ortodoxo: según X. Tilliette (2003, p. 255), "Fichte ha afirmado ciertamente la identidad substancial del cristianismo y de la Doctrina de la Ciencia que constituye un cristianismo depurado"; en palabras de F. Gili (2007, p. 204),

no debemos afirmar, pues, que la religión sea sólo un estadio transitorio para la consecución de la Doctina de la Ciencia completa; por el contrario, la religión juega un papel fundamentalmente filosófico para poder prestar atención legítimamente a lo oculto e inconcebible.

La lectura de izquierda sostiene la independencia completa de la racionalidad filosófica respecto a religión y, por tanto, la definitiva superación de lo religioso; en palabras de R. Marszalek (2006, p. 128):

el progreso se encamina hacia una absorción completa de la fe por el entendimiento, se orienta a la conversión de la fe en una intelección clara y, con ello, a una división sin concesiones de ambos principios; en las últimas formulaciones de Fichte se ve cómo la aparente religiosidad profunda en la Doctrina de la Ciencia tardía es meramente verbal.

En el centro de ambas parece situarse Ch. Asmuth (1999, p. 126): “la teoría fichteana del cristianismo no se dirige a valorar su propia filosofía por su acuerdo con el cristianismo, sino a la inversa, a asegurar al cristianismo una pretensión de verdad por la demostración de su contenido racional". Dirimir entre estas lecturas es harto difícil, si no imposible. A la vista de los textos fichteanos y la reconstrucción que hemos ofrecido hasta aquí pueden hallarse argumentos en pro de cada una de ellas según qué lado se acentúe de la temática: lo fáctico-histórico o lo metafísicoracional.

En lugar de decidir entre esas interpretaciones puede resultar más fructífero atender a un punto omitido por ellas: la relación que establece Fichte entre el cristianismo (y su educación del género humano) y el momento final de la racionalidad filosófica sólo tiene sentido respecto una cierta noción de lo racional (y, por tanto, de lo científico). Ello se hace patente si retomamos la comparación con Lessing: formalmente ambos autores sostienen la traducción racional de las enseñanzas de Cristo, pero no están hablando materialmente de la misma racionalidad ni comprensión de la filosofía. Como se evidencia en los diversos ensayos teológicos y metafísicos de Lessing, su intento por traducir los dogmas cristianos a nivel filosófico se sitúa en el marco conceptual de Spinoza y Leibniz: se trataría de reducir las verdades de hecho de las religiones positivas a una verdad de razón more spinoziano. 
Pues bien, para Fichte tal racionalidad no es más que la ilusión vacía de contenido de un pensar formulario que "pretende nada menos que ampliar su esfera creando, por la fuerza de sus silogismos, nuevos objetos del pensar" (RAF, 111); y, cuando tal filosofía pretende expresar lo real, por su naturaleza formal-objetivadora no puede más que construir sistemas deterministas y dogmáticos opuestos radicalmente a la Doctrina de la Ciencia. La misma observación vale para los pasajes en que Fichte sostiene que la filosofía vierte el contenido del cristianismo en la forma exigida por el entendimiento (VaPh, 158) o por el saber (SL, 389): la cientificidad de que se habla aquí es exclusivamente aquel "ver la ley por la que un cierto ser tiene lugar: conocimiento genético". Por tanto, la relación entre cristianismo y filosofía en Fichte sólo puede esclarecerse adecuadamente si tenemos en cuenta que no hablamos de la razón en general - si es que existe tal cosa -, sino del proceder genético inherente, al menos, a la Doctrina de la Ciencia de la segunda época.

¿Qué caracteriza, no ya las tesis concretas, sino la forma de operar del conocimiento genético? La respuesta es clara y precisa: es un modo de ver. Ver significa dirigir la mirada de cierta manera. Según el ángulo de visión y el enfoque, se ve algo o no, comparece a la mirada una cosa u otra. Pues bien, la visión filosófica, contrapuesta a la visión no-filosófica (VaPh, 19), consiste en tener una clara y diáfana Ein-sicht, una mirada que lee dentro [inte-lectio]. La mirada común (dogmatismo, naturalismo) se limita a ver el "ser muerto, fijo y subsistente" (VaPh, 19) y, por tanto, ve los objetos pero no los procesos constituyentes que los hacen posibles. La mirada filosófica ve que las cosas sólo pueden aparecer en el esquematizar de la conciencia i.e. que las cosas, en verdad, son "imágenes o conocimientos como determinaciones de la conciencia" (VaPh, 21) - y que el esquematizar es producto de la disociación [Entspaltung] originaria en que lo Absoluto exasiste en la conciencia: ${ }^{15}$ la filosofía "entiende el conocimiento en su origen" y así "ve su propio hacerse, es conocimiento genético" (VaPh, 22). Por ello, en lugar de aquel ser muerto, ve "un ser espiritual, libre, viviente, que sólo se hace imagen determinada mediante la limitación de la libertad” (VaPh, 19). Pues bien, para que esta construcción genética pueda llevarse a cabo se requiere de entrada, antes de la reflexión sistemática de la Doctrina de la Ciencia, que el sujeto ya sienta en sí mismo su pertenencia al Absoluto y a la vez su distancia de él, que se sienta imagen de Dios en su doble sentido de identidad y diferencia. Este sentirse sintiendo la pertenencia a lo Absoluto es el "órgano de sentido espiritual” (AsL, 68), es "el ojo de su vida, que él no ve [...], pero a través del cual ve todo cuanto ve" (PhM, 449): sólo este sentimiento nos da el ángulo de visión requerido para ver lo verdadero. Aquí radica aquel "sentido natural de la

15 Valga esta descripción como síntesis del núcleo de Doctrina de la Ciencia de la segunda época: Widmann (1977) es un excelente estudio sobre la exposición de 1804, y Janke (1999) ofrece una reconstrucción sistemático-histórica de la exposición de 1805. 
verdad" presente inmediatamente en la conciencia del que depende la "exposición científica" y en el que la ciencia comprueba su verdad (AsL, 72): el conocimiento genético de la filosofía no es más que la reconstrucción conceptual, mediante esta mirada interior como ôpyavov, de nuestro sentirnos imago Dei.

Ahora bien, por más que la posibilidad de esta mirada intelectiva radique virtualmente en toda conciencia, el legalismo moral-religioso y la disposición ritual del mundo antiguo (con el substancialismo metafísico correspondiente) impedían ejercitarla, pues yacía adormecida por la obediencia ciega a los preceptos y a la autoridad externa. Sólo con la experiencia interna de Cristo y su evangelio de la libertad y de la intimidad con Dios se despertó ese órgano espiritual en el género humano. Se produjo así una auténtica $\mu \varepsilon \tau \dot{\alpha}-v_{0} \alpha$ en el sentido griego originario: no una mera conversio morum, como reza la traducción latina, sino un cambio radical del percibir-comprender que transciende la objetualidad de lo real para ver el mundo como "el material disponible, la esfera sobre la que opera la libertad" (VaPh, 27) para realizar el reino de Dios. Este nuevo modo de ver es precisamente el que hace posible la Einsicht de la Doctrina de la Ciencia: considerar el mundo desde la génesis de la subjetividad en tanto que imagen de lo Absoluto. Sin el poder espiritualmente transformador de la $\mu \varepsilon \tau \dot{\alpha} v o 1 \alpha$ cristiana no dispondríamos (en acto) del órgano de visión necesario para el conocimiento genético. Se entiende así que sólo una filosofía racional-genética puede acoger en su seno el contenido del cristianismo y mostrar su verdad.

Obsérvese ahora lo siguiente. La traducción de las enseñanzas de Cristo a la forma metafísica o genética deja ciertamente atrás la forma inmediata -alegórica, mítica, en suma, su vestimenta narrativa o simbólica - de su aparecer fáctico en la experiencia del fundador y en el símbolo de fe, adoptando la forma superior de la racionalidad demostrativa. Pero lo que nunca queda atrás, porque constituye el ángulo que posibilita la Einsicht y es definitivamente incorporado a ella, es el órgano de visión que nos ha despertado el Cristo de Juan. Aquí lo fáctico se incorpora definitivamente a lo genético: el punto de visión religioso cristiano, para el hombre formado, no es meramente "objeto de su acción, sino, si se me permite expresarlo así, órgano e instrumento de toda su actividad" (PhM, 449). ${ }^{16}$

Si atendemos a este punto capital, la racionalización fichteana del cristianismo la culminación de la educación del género humano - adquiere una tonalidad específica. El filósofo transcendental, o mejor el Wissenschaftlehrer, educa y dirige el progreso humano mediante la claridad de una mirada intelectiva capaz de despertar a sus alumnos para que reproduzcan los actos de autoconocimiento genético en sí mismos:

16 De ahí la afirmación de F. Gili: "la doctrina de la religión (en el sentido de doctrina, intelección y no unión mística) puede iluminar nuestro ojo justo en el punto vivo del que parte la derivación genética filosófica" (2007, p. 204). 
presenta ciertamente una verdad racional - las doctrinas teóricas y prácticas de la filosofía - pero sólo puede exponerlas con toda su certeza demostrativa como llamada [Beruf] o solicitud [Aufforderung] a que los alumnos adopten el ángulo de visión de la Einsicht transcendental, esto es, que produzcan el conocimiento genético por sí mismos y comprueben su verdad en sí mismos. Se introduce así en el corazón de la Doctrina de la Ciencia y como rasgo inseparable de ella, la dimensión proféticoinspirada (como en Cristo o Lutero) propia de una subjetividad para la que Dios es interior intimo meo: ${ }^{17}$ anuncio de un "renacimiento completo en un nuevo mundo superior" (VGB, 327), promesa de una "vida espiritual superior del ser humano" (VGB, 312), transfiguración del sujeto en "auténtica fuerza fundamental que forma mundo" (VaPh, 30). Por ello el Wissenchaftlehrer no es meramente un teórico de la ciencia sino un auténtico predicador, sacerdote, miembro de un cuerpo docente que "se constituye por la gracia de Dios" (VaPh, 76). Si hay disolución del símbolo cristiano en la racionalidad genética, es porque esa razón opera con una Einsicht que es indisolublemente $\mu \varepsilon \tau \dot{\alpha} v o 1 \alpha$ al modo cristiano. Puede afirmarse, pues, con J.L. Villacañas (1993, p. 136) que

en la obra de Fichte se presentan todas las características del tipo ideal [weberiano] del carisma aplicadas a la filosofía; el intelectual es, para Fichte, el portador del carisma [...]; este modelo cristiano exige que lo divino viva en la forma de un yo y, consiguientemente, que todo cuanto se manifiesta como divino ha de presentarse en la inmanencia de la interioridad del hombre.

Desde esta perspectiva, lo que tiene lugar en la última fase de educación del género humano no es simplemente una racionalización del cristianismo sino, en todo caso, su transmutación en una peculiar "razón idealista carismática" que es así auténtica transfiguración [Verklärung] de la ilustración [Aufklärung] (Villacañas, 1993, p.146).

Los textos de Fichte obligan, no obstante, a introducir un elemento complementario que compensa, en cierto modo, aquella subjetividad carismática. Dada la dimensión intersubjetiva de la conciencia, el momento inspirado-carismático de la Einsicht se hace letra, a partir del momento fundante, en el símbolo de fe de la comunidad. Atiéndase al término sym-bolon: signo de otra cosa. En su tercera crítica, Kant había detallado cómo en una exposición simbólica el signo visible remite a lo suprasensible, mientras que en una exposición esquemática se refiere a la experiencia objetiva (KU, 351-352). ${ }^{18}$ Frente al carácter regulado y cerrado del

17 R. Lauht subraya así este trasfondo agustiniano en la filosofía de Fichte: "Sería ciertamente insensato aceptar que la gran confrontación entre agustinismo y aristotelismo, que dominó la Edad Media, haya enmudecido simplemente con la mayoría de edad de la filosofía moderna. Eso significaría, sin duda, que en aquella confrontación nada habría habido de realmente fundado en la naturaleza de las cosas. Aquella confrontación ha proseguido y no es realmente demasiado difícil encontrar de nuevo el aristotelismo en el sistema de Hegel y el agustinismo en el de Fichte" (1963, p. 269).

18 Citamos a Kant según se indica en la bibliografía. Las traducciones son mías. 
esquema, el símbolo es una exposición que activa las ideas estéticas de la imaginación y, apuntando de forma abierta a lo suprasensible, "da mucho que pensar" (KU, 314). Por eso, cuando Fichte sostiene la perfectibilidad del símbolo (SL, 385), señala que lo expresado en él se abre a una dinámica interpretativa por avanzar progresivamente en su clarificación. La comunidad eclesial no se identifica literalmente con el símbolo de fe, sino que, dado el exceso significativo de lo simbólico, lo reinterpreta y reactualiza: su identidad consiste, en cierto modo, en una continuidad hermenéutica que se nutre de la fuente originaria que la funda. Y, en efecto, Fichte explicita cuál es el único criterio que puede regir la exégesis de los textos fundacionales: "comprenderlos como si efectivamente hubieran querido decir algo y, en la medida que lo permiten sus palabras, como si hubieran dicho lo correcto y verdadero" (AsL, 116), esto es, que, a través de lo alegórico, metafórico o mítico de la expresión simbólica, hay algo que pensar que debe ser progresivamente desvelado. Evangelios, primeros concilios, iglesia medieval y Reforma, pero también la Doctrina de la Ciencia como su resultado racional, no son a la postre más que momentos sucesivos de esta continuidad histórica de reactualización del símbolo originario.

Desde esta perspectiva la relación entre el cristianismo y su culminación en la intelección racional se muestra próxima a la comprensión de la tradición formulada por Gadamer: sin el horizonte abierto por las posibilidades interpretativas del símbolo fundante no sería posible la Einsicht filosófica y, en este sentido, la educación del género humano es un proceso permanente de reactualización de aquella potencialidad significativa originaria. Fichte lo expresa nítidamente: "todo nuestro tiempo y todas nuestras investigaciones están situados sobre el suelo del cristianismo y de él han surgido [...], no seríamos absolutamente nada de lo que somos si este poderoso principio no nos hubiera precedido en el tiempo" (AsL, 122). Es más, el carácter determinante del símbolo como eje de esta tradición no ha de entenderse a modo de una decisión voluntaria por parte de los miembros de la cadena histórica, sino que todo miembro se encuentra ya de entrada siendo lo que es porque pertenece a la cadena y comparte su horizonte comprensivo. En términos de Fichte: se trata de un "dominio universal inconsciente" del símbolo a modo de "auténtico principio impulsor de la vida pública” (GgZ, 369-370). Y añade, subrayando aún más el carácter de supuesto último e implícito de esa fuente originaria de sentido: no se trata ya de que "el cristianismo enseñe esto o aquello", sino que "el cristianismo vive verdaderamente y [yace] oculto, de hecho, en la mente de los hombres exteriorizándose en todos sus actos" (GgZ, 370).

En el seno de la tradición abierta por el Cristo joánico y el consiguiente símbolo de fe se ha educado el género humano. Y esa educación está alcanzando finalmente la clarividencia racional acerca de la verdad que radicaba en el mensaje evangélico en su oposición al mundo antiguo. La Doctrina de la Ciencia y su cristianismo racional 
son, a la postre, la reconstrucción intelectivo-genética de lo que fácticamente nos constituye desde el origen. ¿Círculo virtuoso hermenéutico o círculo vicioso lógico? Para el Wissenschaftlehrer tal círculo sería la prueba de su verdad, ya que lo fáctico y lo genético son dos aspectos del $a l s^{19}$ en que se manifiesta lo Absoluto, en tanto que historia y en tanto que intelección, pues Dios no puede exteriorizarse más que en la disociación: "el mundo es la imagen de Dios, y tal como el mundo es, es su imagen entera y nunca puede devenir, no puede ser creado un nuevo ser; si bien, no obstante, el ser uno se despliega paulatinamente hacia la conciencia” (SL, 392). Para quien no se ha elevado a la plena intelección filosófica, bastaría con recordarle que "no podemos prescindir de parte alguna de nuestro ser, herencia de acontecimientos anteriores, y ninguna persona sensata se preocupa por investigar qué existiría si no existiera lo que existe" (AsL, 122).

\section{Referencias}

\section{Fuentes}

Fichte, J.G. (1964ss). Gesamtausgabe. Stuttgart/Bad Constatt: Bayerische Akademie der Wissenschaften.

Hemos citado las obras de Fichte indicando la abreviatura del título y el número de página del volumen respectivo de la GA, que se indican aquí:

AsL: Anweisung zum seeligen Leben (vol. I/9).

B: Briefe (GA, III/1).

BfR: Beiträge zur Berichtigung der Urteile des Publikums über die Französische Revolution (GA I/1).

GgZ: Die Grundzüge des gegenwärtigen Zeitalters (vol. I/8).

PhM: Philosophie der Maurerei. Briefe an Konstant (GA, I/8).

RAF: Rückerinnerungen, Antworten, Fragen (GA, II/5).

RD: Die Republik des Deutschen (GA, II/10).

RdN: Reden an die Deutsche Nation (GA, I/10).

SL: Sittenlehre (vol. II/13).

VaPh: Vorlesungen aus der angewendeten Philosophie (vol. Il/16).

VGB: Vorlesungen über Geist und Buchstabe in der Philosophie (GA, II/3).

WG: Über das Wesen des Gelehrten (GA, I/8).

Kant, I. (1968). Kritik der Urteilskraft. Akademie-Textausgabe, vol. V. Berlín: Walter de Gruyter.

Citamos el texto con la abreviatura KU seguida de la página del volumen.

19 Estructura que define, en la Doctrina de la Ciencia de 1805, el momento de aparición de la unidad absoluta como disociación en la conciencia. 
Lessing, G.E. (1965). Die Erziehung des Menschengeslechts. Stuttgart: Reclam.

El texto es citado con la abreviatura EM y el número de parágrafo.

\section{Literatura secundaria}

Andreu, A. (1982). “Notas al pie de página”. En: Lessing, G.E. Escritos filosóficos y teológicos. Traducción de A. Andreu. Madrid: Editora Nacional.

Asmuth, Ch. (1999). Das Begreifen des Unbegreiflichen. Philosophie und Religion bei J.G. Fichte 1800-1806. Stuttgart: Frommann Verlag.

Barr, H. (2013). “Gotthold Ephraim Lessing”. En: Hofmann, M. (ed.). Aufklärung. Epoche, Autoren, Werke. Darmstadt: Wissenschaftliche Buschgesellschaft.

Brito, E. (2004). J.G. Fichte et la transformation du christianisme. Lovaina: University Press \& Peeters.

Bultmann, R. (1958). Theologie des Neuen Testaments. Tubinga: J. Mohr.

Cassirer, E. (1943). Filosofía de la Ilustración. Traducción de E. Ímaz. México: FCE.

Fuchs, E. (1978). Fichte im Gespräch. Berichte der Zeitgenossen (vol. I). Stuttgart: Frommann Verlag.

Gili, F. (2007). Die Präsenz der "Populärphilosophie" im Spätwerk Fichtes. FichteStudien, 31, 195-204.

Janke, W. (1999). J.G. Fichtes Wissenschaftslehre 1805. Darmstadt: Wissenschaftliche Buchgesellschaft.

Jeremias, J. (1971). Neutestamentliche Theologie. Gütersloh: G. Mohn.

Lauth, R. (1963). Die Bedeutung der Fichteschen Philosophie für die Gegenwart. Philosophisches Jahrbuch, 70, 252-270.

Léon, X. (1922). Fichte et son Temps (3 vols.). París: Arman Colin.

Marszalek, R. (2006). Fichtes Religionstheorie im Licht der Schellingschen Gedanken zur Mythologie. Fichte-Studien, 26, 121-129.

Rametta, G. (2003). “Doctrine de la science et Doctrine de l'État. La dissolution de la théologie politique chez le dernier Fichte". En : Goddard, J.Ch. y Maesschalck, M. (eds.). Fichte. La philosophie de la maturité. París: J. Vrin.

Tilliete X. (2003). Fichte. La science de la liberté. París: J. Vrin.

Turró, S. (2013). La idea de Europa en Fichte. Anales del Seminario de Historia de la Filosofía de la Universidad Complutense, 30, 107-135.

Turró, S. (2017). "Estudio preliminar". En: Fichte, J.G. Lecciones sobre filosofía aplicada. Doctrina del Estado. Traducción de S. Turró. Salamanca: Sígueme.

Turró, S. (2019a). El establecimiento del reino de la razón. Argumenta Philosophica, $1,53-69$.

Turró, S. (2019b). “Estado, cristianismo e historia en Fichte”. En: Ferrer, D. (ed.). A Filosofia da História e da Cultura em Fichte. Coimbra: Imprensa da Universidade 
de Coimbra.

Widmann, J. (1977). Die Grundstruktur des transcendentales Wissens nach J.G. Fchtes Wissenschaftslehre 1804. Hamburg: Meiner.

Villacañas, J.L. (1993). Fichte und die charismatische Verklärung der Vernunft. Fichte-Studien, 5, 117-148.

Vollhardt, F. (2018). Gotthold Ephraim Lessing. Epoche und Werk. Gotinga: Wallstein Verlag.

Recebido em: 30.03 .2020

Aceito em: 21.05.2020

Esta obra está licenciada com uma Licença Creative Commons Atribuição-NãoComercial- 